\title{
Jurnal Teknologi
}

\section{Measurement of Effectiveness and Difficulty of Traffic Management Measures in Disasters}

\author{
Anil Minhans $\mathrm{a}^{*}$ \\ ${ }^{a}$ Faculty of Civil Engineering,Universiti Teknologi Malaysia, 81310 UTM Johor Bahru, Johor, Malaysia \\ *Corresponding author: anilminhans@utm.my
}

Article history

Received :10 May 2013

Received in revised form :

25 September 2013

Accepted :15 October 2013

\section{Graphical abstract}

\begin{tabular}{cccc}
\hline Priority Classes & \multicolumn{2}{c}{ Effectiveness } & Difficulty \\
\cline { 2 - 4 } & Score & Score \\
\hline First Priority Group & I & $E S>2,0$ & $(0,5<D S<<1,5)$ \\
\hline Second Priority Group & II & $E S \leq 2,0$ & $(0,5<D S<1,5)$ \\
\hline Third Priority Group & III & $E S>2,0$ & $(1,5 \leq D S<2,0)$ \\
\hline Fourth Priority Group & IV & $E S \leq 2,0$ & $(1,5 \leq D S<2,0)$ \\
\hline Fifth Priority Group & V & $E S>2,0$ & $(2,0 \leq D S<2,5)$ \\
\hline Sixth Priority Group & VI & $E S \leq 2,0$ & $(2,0 \leq D S<2,5)$ \\
\hline
\end{tabular}

\begin{abstract}
Traffic managers view disasters as events depicting sudden surge in traffic demand and deficient transport supplies. In disasters, increments of transport capacities by transport-related development are impractical and traffic management measures are viable yet inexpensive options to mitigate the effects of disasters. This paper presents the methodology of qualitative assessment conducted on 27 pre-selected traffic management (TM) measures that are applicable to disasters. The methodology of the assessment includes: (i) estimation of relative weight of traffic management factors using analytic hierarchy process (AHP), (ii) self-assessment and rating of measures based on effectiveness and difficulty scales, (iii) determination of priority classes of measures based on qualitative assessment model, and (iv) the determination of residual measures signifying low applicability. Such an assessment aids decision-making process regarding the selection of measures and their applicability in the event of real disasters. The results from the assessment indicated that all the 27 measures were found effective in disasters, seven of them were not found applicable, thereby leaving only 20 measures, which were found both effective and applicable.
\end{abstract}

Keywords: Traffic management measures; disaster management; qualitative assessment model; analytic hierarchy process; effectiveness and applicability

\subsection{INTRODUCTION}

Disasters need timely response in order to minimize the consequent damage. One of the critical concerns in evolving an effective disaster management strategy is to determine effectiveness and applicability of traffic management measures. In most cases, traffic management is one of the most important disaster management functions responsible for the mitigation, preparedness, response and recovery related to disasters. Therefore, assessment of traffic management measures is essential to ensure their applicability in disasters. Where field studies are more resource-intensive and unfeasible in many cases, qualitative assessment methods are increasingly being considered suitable for decision-making purposes. Furthermore, these methods are even more acceptable and dependable where experts from the same fields are involved. In this study, a total of 30 experts in the field of traffic engineering and transport planning from Germany, India, Japan and Vietnam were involved to provide their opinion on traffic management goals, objectives (factors and criteria of assessment) and measures for disasters.

This paper is organized into two broad sections. While the first section provides the brief introduction of traffic management measures in cases of disasters, and the other section deals with the qualitative assessment of the selected measures. Although, the full description of traffic management measures is beyond the scope of this paper, they are discussed and described based upon their specific requirements to implementation.

In the section of qualitative assessment, two broad qualitative assessments are performed and explained in this paper. The first qualitative assessment is aimed at obtaining the relative weights of importance provided by the experts regarding the importance given to traffic management factors and their descendent criteria (goals and objectives) in cases of disasters. The second qualitative assessment is a self-conducted assessment of individual measures based upon the effectiveness of measures and difficulty of implementation of measures. Although the assessment performed on measures is entirely based on the qualitative data yet the possible quantitative indicators were serendipitously identified which could be useful in other studies to indicate the fulfillment of the criteria of traffic management factors when available.

Finally, the qualitative assessment model is developed which uses results of both the assessments and provides effectiveness and difficulty scores. These scores are later used to form six priority classes of traffic management measures based on high, medium or 
low levels of effectiveness and difficulty. The inferences derived from the assessment results are also discussed.

\subsection{TRAFFIC MANAGEMENT MEASURES}

A total of 27 traffic management measures are pre-selected for assessment which bears the potential for effective application in the management of disasters. During the selection of measures, literature was extensively reviewed and only those measures with previously documented effectiveness in disaster situations were selected. Although the selected measures were proven effective in many disasters yet the measures are later evaluated for their effectiveness and applicability based upon the qualitative assessment model. Only those traffic management measures that conformed to the disaster response and disaster recovery are selected. These include 8 public transport measures ${ }^{\mathrm{i}}, 2$ nonmotorised transport measures ${ }^{\mathrm{ii}}, 4$ individual motorised transport measuresiii, 10 multi-modal and inter-modal transport measures $(\mathrm{MIM})^{\mathrm{iv}}$ and a total of 3 freight transport measures $(\mathrm{FT})^{\mathrm{v}}$. Subsequently, these measures are ranked based on their effectiveness and applicability for disaster situations. In order to avoid false interpretation and facilitate understanding about the expectation from traffic management measures especially for disaster cases, these were classified based upon necessary five categories of requirements of implementation.

Table 1 Classification of traffic management measures by requirements

\begin{tabular}{|c|c|c|c|c|c|c|}
\hline S.No. & Traficic Management Measures & 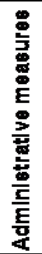 & 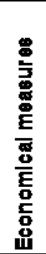 & 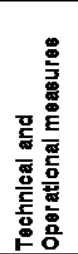 & 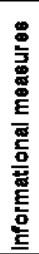 & 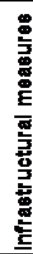 \\
\hline$\overline{P T}$ & Public Transport Measures & & & & & \\
\hline 1 & Public Transport Network Improvement & & & $\bar{X}$ & & $\bar{X}$ \\
\hline 2 & Public Transport Scheduling Improvement & & & $\mathrm{X}$ & $\mathrm{X}$ & \\
\hline 3 & Public Transport Accessibility Improvement & $\mathrm{X}$ & & $\bar{x}$ & & \\
\hline 4 & Public Transport Capacity Improvement & & & $\bar{x}$ & & $\bar{X}$ \\
\hline 5 & Special Disaster Transport Services & & $\mathrm{X}$ & $\mathrm{X}$ & & \\
\hline 6 & Public Transport Right-of-Way Prioritisation & $\bar{X}$ & & $\bar{X}$ & & \\
\hline 7 & Public Transport Information Services & & & $\bar{X}$ & $\overline{\mathrm{X}}$ & \\
\hline 8 & Public Transport Management Centre & $\mathrm{X}$ & & $\bar{X}$ & $\mathrm{X}$ & \\
\hline NMT & Non-Motorised Transport Measures & & & & & \\
\hline 1 & Establishment of Pedestrian routes \& Facilities & & & $\bar{X}$ & & $\bar{x}$ \\
\hline 2 & Establishment of Bicycle routes \& Facilities & & & $\bar{X}$ & & $\bar{x}$ \\
\hline IMT & Individual Motorised Vehicle Measures & & & & & \\
\hline 1 & Carpooling \& other Ride Sharing Programs & $\mathrm{X}$ & $\mathrm{X}$ & & & \\
\hline 2 & Car Rental Services & $\mathrm{X}$ & $\mathrm{X}$ & & & \\
\hline 3 & Automobile Roadway Repair Service & & $\mathrm{X}$ & & & $\bar{x}$ \\
\hline 4 & Special Traffic Rules Enforcement & $\mathrm{X}$ & & $\bar{X}$ & & \\
\hline MIM & Multimodal and Intermodal Transport Measures & & & & & \\
\hline 1 & Economic or Preferential Incentives & $\mathrm{X}$ & $\mathrm{X}$ & & & \\
\hline 2 & Trip reduction \& Land-use Modification Ordinances & $\mathrm{X}$ & & $\bar{X}$ & $\bar{X}$ & \\
\hline 3 & Road Network Control & & & $\bar{X}$ & & $\bar{X}$ \\
\hline 4 & Road Section Control & & & $\bar{X}$ & & $\bar{x}$ \\
\hline 5 & Improvement of Signalised Traffic Control & & & $\bar{X}$ & & $\bar{x}$ \\
\hline 6 & Improvement of Non-signalised Traffic Control & & & $\bar{X}$ & & $\bar{x}$ \\
\hline 7 & Improvement of Inter-modal and Parking Facilities & & & $\bar{X}$ & & $\overline{\mathrm{X}}$ \\
\hline 8 & Traffic \& Disaster Information Service & & & $\bar{X}$ & $\mathrm{X}$ & \\
\hline 9 & Disaster Traffic Management Centre & & & $\mathrm{X}$ & $\mathrm{X}$ & \\
\hline 10 & Work-Zone Coordination \& Management Centre & & & $\mathrm{X}$ & $\mathrm{X}$ & \\
\hline$\overline{F R}$ & Freight Transport Measures & & & & & \\
\hline 1 & City Logistics System & $\bar{X}$ & & $\bar{X}$ & & \\
\hline 2 & Household Goods Delivery Transport System & $\bar{X}$ & & & $\bar{X}$ & \\
\hline 3 & Freight Traffic Operations Control & & & $\bar{X}$ & & \\
\hline Note: & $\begin{array}{l}\text { Administrative measures include legal, political, plann } \\
\text { Economic measures include preferential incentives fo } \\
\text { Technical and operational measures include signalis } \\
\text { modifications, prioritisation, scheduling, speed reduction }\end{array}$ & \multicolumn{4}{|c|}{$\begin{array}{l}\text { Technical and operational measures include signalisation, patrol, surveillance, geometric } \\
\text { modifications, prionitisation, scheduling, speed reduction, manual traffic control etc. }\end{array}$} & \\
\hline
\end{tabular}

i Public transport (PT) measures are aimed at patronising the use of public transport and its associated services. The implementation of public transport measures are advocated in urban situations which experience a high use of IMT modes and a heterogeneous mix of traffic.

ii Non-motorised transport (NMT) measures are aimed at the provision of adequate right-of-way for such non-motorised transport modes as bicycles and pedestrians. The NMT measures include the provision of adequate facilities and the safe environment for the operations of both pedestrian and bicycle traffic. Such measures are implemented to harness the potential of cycling and walking to limit the use of individual motorised transport modes for short trips.

iii Individual motorised transport (IMT) measures are aimed at improving the traffic flow conditions and efficiency of private transport. Thus, the IMT measures improve traffic safety, transport economy and transport environment. iv Inter-modal transport measures are aimed at the provision and organisation of inter-modal facilities especially the parking and transfer points for the purpose of promoting the use of high capacity or high occupancy transport modes (PT and IMT). Multi-modal transport measures are aimed at the improvement of the traffic flow conditions by the multiple modes by a single application of measure. This category includes measures such as application of green-wave for all road transport modes and pre-emption of traffic using traffic signal control. For the purposes of this study, both intermodal and multi-modal transport measures (MIM) are combined to form a single category of measures.

v Freight transport (FT) measures are mostly aimed at minimising the conflicts between FT and other modes. This category also involves the use of available capacities of FT modes by coordinating different FT operators. In addition, the measures that reduce the environmental impacts of freight transport are also covered in this category. 
These five categories of requirements are: (i) administrative and organisational requirements, (ii) economic requirements, (iii) technical and operational requirements, (iv) information requirements, and (v) infrastructure requirements (Table 1). Thus, the measures can be classified based on the categories of requirements of resources. The resultant categories of TM measures are administrative and organisational measures, economic measures, technical and operational measures, and information measures. In general, the administrative and organisational measures are focused on ensuring the enforcement of laws and regulation. This category includes organisational measures that improve the public acceptance and institutional participation. The economic measures are focused on providing economic incentives or disincentives to control the uses of particular transport modes. The technical and operational measures are focused on implementing appropriate traffic control or traffic information dissemination to influence the traffic flow, road users or traffic and transport processes.

Table 2 Numerical scale for pair-wise comparison

\begin{tabular}{lc}
\hline \multicolumn{1}{|c}{ Verbal Expression } & $\begin{array}{c}\text { Numerical } \\
\text { Scale }\end{array}$ \\
\hline Equal Importance or equal desirability of alternatives & 1 \\
\hline $\begin{array}{l}\text { Moderate importance of one attribute over another or } \\
\text { moderate desirability of one alternative over another }\end{array}$ & 1.5 \\
\hline $\begin{array}{l}\text { Significant importance of one attribute over another or } \\
\text { strong desirability of one alternative over another }\end{array}$ & 2 \\
\hline $\begin{array}{l}\text { Extreme importance of one attribute over another or very } \\
\text { strong desirability of one alternative over another }\end{array}$ & 2.5 \\
\hline
\end{tabular}

This category includes traffic engineering measures. Information measures are focused on changing the travel decisions of road users such as time of travel, mode of travel, route of travel, destination of travel and travel speeds through the dissemination of pre-trip or on-trip traffic information. These measures are further clarified by the aim of the measure, the intended impacts of the measures, mechanisms involved in the measure implementation and the required devices for the measure implementation.

\subsection{QUALITATIVE ASSESSMENT OF TRAFFIC MANAGEMENT MEASURES}

The qualitative assessment of measures involves two estimations; the first estimation of relative weights of importance of a total of 8 traffic management assessment factors (4 factors each for effectiveness and difficulty assessment) and their corresponding criteria. These relative weights of factors are obtained from the traffic experts by conducting an expert-opinion survey (Figure 1). Four effectiveness assessment factors selected for the effectiveness assessment of measures are: (i) transport accessibility and mobility; (ii) transport safety and security; (iii) transport economy and (iv) transport environment.

These factors directly reflect the necessary goals and objectives of traffic management in disasters. The descendent criteria of effectiveness assessment for each effectiveness assessment factor are given in Table 3. This assessment recognizes the fact that effectiveness of measures does not directly relate to applicability of measures. Therefore, all measures have to undergo a difficulty assessment to confirm the applicability of measures in the local environment. It is important to note here that the applicability is the reciprocal of difficulty.
Four difficulty assessment factors selected for the difficulty assessment of measures are: (i) transport costs (affordability); (ii) technical systems; (iii) institutional participation and (iv) public acceptance. Likewise, the descendent criteria of difficulty assessment factors under each difficulty assessment factor are given in Table 4.

A questionnaire containing twenty-three questions in three parts is composed. The first part provides the personal information of the traffic expert. The second part of the questionnaire is aimed at obtaining both the subjective opinions on the importance of traffic management factors and their corresponding descendent criteria of assessment in cases of disasters. Similarly, the third part of the questionnaire is aimed at obtaining the subjective opinions on difficulty of implementation of measures based on four difficulty factors given above. Relative factor weights are likewise obtained for the criteria of difficulty assessment. The obtained opinions are then analysed using an analytic hierarchy process (AHP) technique for the calculation of final relative weights of importance in percentages (see Table 3 and Table 4) [5] [6]. The obtained relative weights of importance are then fixed for the further analyses.

The second estimation involved a self-conducted assessment of 27 pre-selected TM measures. This estimation involves ratings based on the fulfilment of criteria of assessment for both effectiveness and difficulty. Four rating scales from 0 to 3 are used to denote the effectiveness and difficulty of measures based on the given description of a measure (e.g. Table 6). Both assessments gave high rank to measures that involve high impacts, direct fulfillment of criteria, large scale of application, supplementary effect etc. The high ranks for difficulty were associated with moderate to high scale of difficulties, direct effect on the applicability of measure, city level modification of operation and control systems, need of high subsidies, and involvement of multiple organizations. 


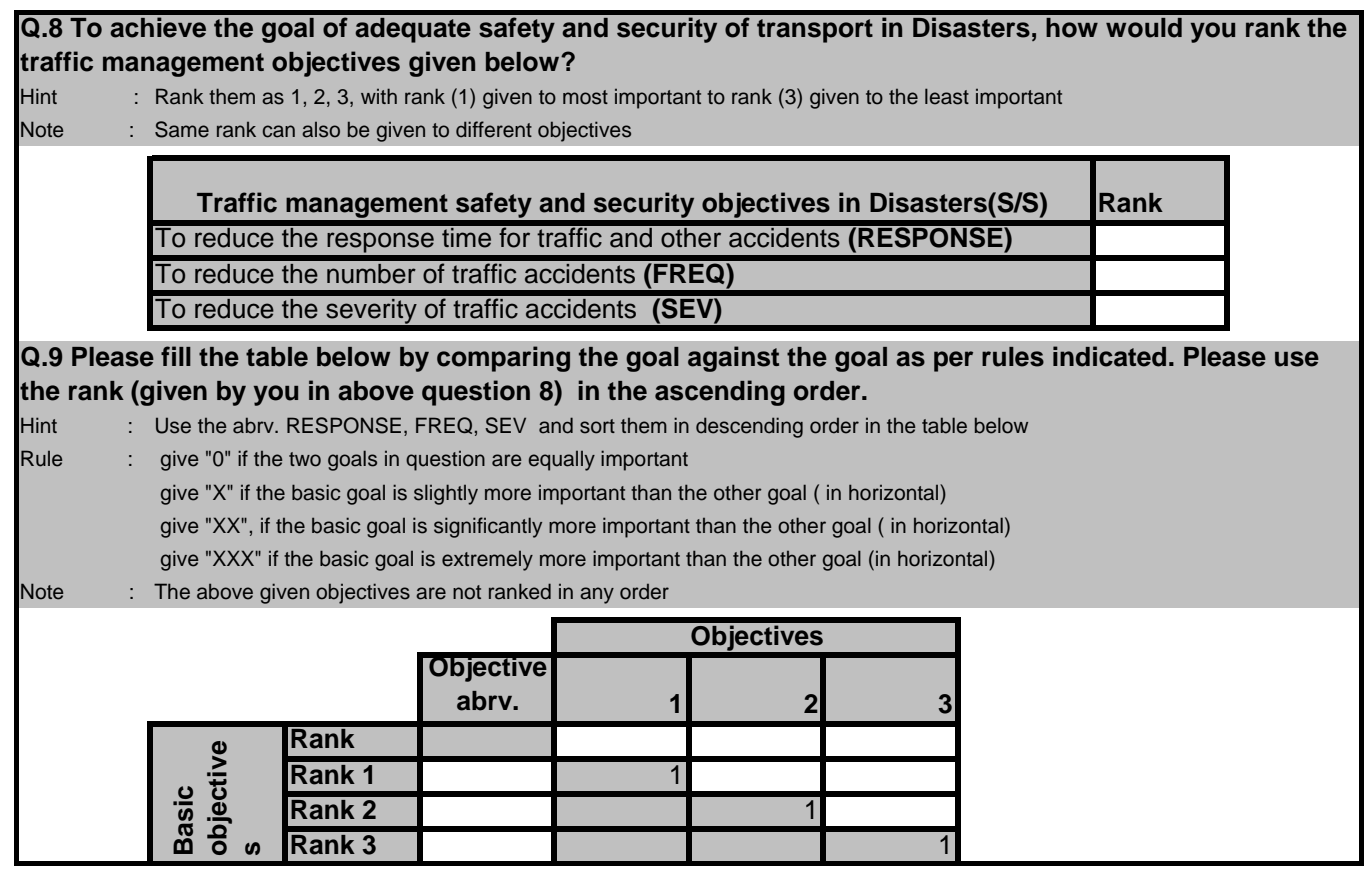

Figure 1 A sample of expert-opinion survey

Finally, effectiveness and difficulty scores are calculated by using the formulae given in the next sections (Formula 1 and Formula 2). The obtained scores from effectiveness and difficulty assessment are reviewed and priority classes are formed by assigning rules. Six priority classes thus formed indicate varying levels of effectiveness and difficulties. The first priority class includes measures with best effectiveness scores (ES> 2.0) and least difficulty scores (DS < 1.5). An availability of a catalog of measures based on the given assessment is a decision-making support to the stakeholders of disaster management including traffic management. In the following sections both the estimations are explained.

Table 3 Relative weights of TM effectiveness factors and criteria of assessment

\begin{tabular}{|c|c|c|c|c|}
\hline $\begin{array}{l}\text { TM effectivenss } \\
\text { assessment } \\
\text { factors }\end{array}$ & $\begin{array}{l}\text { Factor } \\
\text { weights }\end{array}$ & $\begin{array}{c}\text { Criteria of assessement } \\
\text { (TM objectives) }\end{array}$ & $\begin{array}{l}\text { Criteria } \\
\text { weights }\end{array}$ & $\begin{array}{c}\text { Resultant } \\
\text { weights of } \\
\text { criteria }\end{array}$ \\
\hline \multirow{4}{*}{$\begin{array}{l}\text { Transport } \\
\text { Accessibility and } \\
\text { Mobility }\end{array}$} & \multirow{4}{*}{$38 \%$} & Promotion of equity of transport & $28 \%$ & $10.6 \%$ \\
\hline & & Increase of number of routes & $23 \%$ & $8.7 \%$ \\
\hline & & Increase of number of modes & $22 \%$ & $8.4 \%$ \\
\hline & & Increase of transport capacity & $27 \%$ & $10.3 \%$ \\
\hline \multirow{3}{*}{$\begin{array}{l}\text { Transport Safety and } \\
\text { Security }\end{array}$} & \multirow{3}{*}{$30 \%$} & $\begin{array}{l}\text { Reduction of response time of traffic } \\
\text { and other accidents }\end{array}$ & $33 \%$ & $9.9 \%$ \\
\hline & & $\begin{array}{l}\text { Reduction of number of traffic and other } \\
\text { accidents }\end{array}$ & $38 \%$ & $11.4 \%$ \\
\hline & & $\begin{array}{l}\text { Reduction of severity of traffic and } \\
\text { other accidents }\end{array}$ & $29 \%$ & $8.7 \%$ \\
\hline \multirow{2}{*}{ Transport Economy } & \multirow{2}{*}{$19 \%$} & Reduction of total transport costs & $49 \%$ & $9.3 \%$ \\
\hline & & Maximisation of transport efficiency & $51 \%$ & $9.7 \%$ \\
\hline \multirow{3}{*}{$\begin{array}{l}\text { Transport } \\
\text { Environment }\end{array}$} & \multirow{3}{*}{$13 \%$} & $\begin{array}{l}\text { Minimisation of consumption of energy } \\
\text { resources }\end{array}$ & $38 \%$ & $4.9 \%$ \\
\hline & & Reduction of air pollution & $36 \%$ & $4.7 \%$ \\
\hline & & Reduction of noise pollution & $26 \%$ & $3.4 \%$ \\
\hline
\end{tabular}




\subsection{Estimation of Relative Weights of Importance Using} Analytic Hierarchy Process

The purpose of obtaining relative weights of importance is for priori classification and ranking of traffic management factors. The calculated weights of importance indicate the importance of the factors and emphasises their contribution in the success of traffic management in disasters. The relative weights of importance are calculated in percentages using a mathematical technique called Analytic Hierarchy Process. The AHP is a widely used technique for multi-criteria decision analysis.

This technique enables people to make decisions which involve multiple concerns of planning, setting priorities, selecting the best among a number of alternatives and allocating resources [5] [6].

The AHP technique has been employed in this study to obtain weights of importance based on the intuitive judgments of traffic experts. This technique involves a pair-wise comparison of different alternatives, which are traffic management factors and criteria of assessment in this study. Although AHP technique can use three approaches for specifying pair-wise comparison which are: numerical, graphical and verbal mediated; the numerical technique is employed due to the limitations of the study. For a numerical approach the participant of the interview (in this study a traffic expert) answered each question with a number, for example, a number 2.5 is assigned when "attribute $\mathrm{x}$ (factor $\mathrm{x} 1$ ) is extremely important or desirable when compared to attribute y (factor $\mathrm{x} 2$ )". Four-point numerical scales are used with 0.5 scale interval between the scales elements to present variations (see Table 2).

The pair-wise comparison of traffic management factors of assessment is examined individually to determine the relative weights of importance in percentage for each traffic expert. The final weights of importance of each TM factor and corresponding criteria of assessment are estimated by calculating the geometric mean of the percentages of individual weights of importance of all selected traffic experts [4]. The geometric mean is defined as the nth root of the product of $n$ values. The geometric mean is useful in finding the average of percentages, ratios, indexes, or growth rates [1] [4].

The AHP technique is used only for estimating the relative weights of importance traffic management factors and criteria for the assessment. In the next estimation the TM measures are not compared, however the effectiveness as well as the difficulty of a measure is based on the description of level-of-effectiveness and level-of difficulty.

The result of the analysis of relative weights of importance for effectiveness factors indicates the following: (i) the transport accessibility and mobility factor is rated as the most important factor which has a relative weight of $38 \%$; (ii) the transport safety and security factor is rated as the second important factor which has a relative weight of $30 \%$; (iii) the transport economy factor is rated as the third important factor which has a relative weight of $19 \%$, and (iv) the transport environment factor is rated as the fourth important factor which has a relative weight of $13 \%$ respectively.

Similarly, the result of the analysis of relative weights of importance for difficulty factors indicates the following: (i) the requirement of transport costs involved in measure implementation is rated as the most difficult factor with a relative weight of $31 \%$; (ii) the requirement of technical systems in the TM measure implementation is ranked second in difficulty with a relative weight of $27 \%$; (iii) the requirement of institutional participation in the TM implementation is ranked third in difficulty with a relative weight of $24 \%$, and (iv) the requirement of public acceptance is ranked fourth and least in difficulty with a relative weight of $18 \%$ respectively.

The relative weights of importance of TM factors and criteria based on TM effectiveness and difficulty assessment factors are given in the Table 3 and Table 4 . The resultant weights of criteria are the relative percentages of importance obtained when all TM factors are considered.

Table 4 Relative weights of TM difficulty factors and criteria of assessment

\begin{tabular}{|c|c|c|c|c|}
\hline $\begin{array}{l}\text { TM difficulty } \\
\text { assessment } \\
\text { factors }\end{array}$ & $\begin{array}{l}\text { Relative } \\
\text { weights }\end{array}$ & Criteria of assessement & $\begin{array}{l}\text { Criteria } \\
\text { weights }\end{array}$ & $\begin{array}{c}\text { Resultant } \\
\text { weights of } \\
\text { criteria }\end{array}$ \\
\hline \multirow{2}{*}{$\begin{array}{l}\text { Required transpart } \\
\text { costs }\end{array}$} & \multirow{2}{*}{$31 \%$} & $\begin{array}{l}\text { Total investment costs involved for } \\
\text { measure implementation }\end{array}$ & $57 \%$ & $17.7 \%$ \\
\hline & & $\begin{array}{l}\text { Total operation costs involved for measure } \\
\text { implementation }\end{array}$ & $43 \%$ & $13.3 \%$ \\
\hline \multirow{2}{*}{$\begin{array}{l}\text { Required technical } \\
\text { systems }\end{array}$} & \multirow{2}{*}{$27 \%$} & $\begin{array}{l}\text { Total operation \& control Systems } \\
\text { involved for measure implemenation }\end{array}$ & $60 \%$ & $16.2 \%$ \\
\hline & & $\begin{array}{l}\text { Total information systems involved for } \\
\text { measure implementation }\end{array}$ & $40 \%$ & $10.8 \%$ \\
\hline \multirow{2}{*}{$\begin{array}{l}\text { Required institutional } \\
\text { participation }\end{array}$} & \multirow{2}{*}{$24 \%$} & $\begin{array}{l}\text { Involvement of transport related } \\
\text { institutions for measure implemenation }\end{array}$ & $41 \%$ & $9.8 \%$ \\
\hline & & $\begin{array}{l}\text { Involvement of political bodies for } \\
\text { measure implemenation }\end{array}$ & $59 \%$ & $14.2 \%$ \\
\hline \multirow{2}{*}{$\begin{array}{l}\text { Required public } \\
\text { acceptance }\end{array}$} & \multirow{2}{*}{$18 \%$} & $\begin{array}{l}\text { Acceptance of transport users for measure } \\
\text { implemenation }\end{array}$ & $47 \%$ & $8.5 \%$ \\
\hline & & $\begin{array}{l}\text { Acceptance of non-transport users for } \\
\text { measure implemenation }\end{array}$ & $53 \%$ & $9.5 \%$ \\
\hline
\end{tabular}

The adopted qualitative rating scales ranges from 0 to 3 , in the increasing order of level of effectiveness or difficulties in fulfilment of various criteria of assessment. Thus, a measure which has a highest level of effectiveness to meet a given criteria of assessment is rated as 3 and similarly, a measure which has a highest level of implementation difficulties (low applicability) based on the criteria of assessment is rated as 3 .

All 27 measures are assessed for 12 criteria of assessment related to effectiveness of measures in fulfilling the factors of assessment. Similarly, 8 criteria of assessment related to difficulty of measures (indicates applicability) are included in the 
measure assessment. The 12 criteria were based on factors of transport accessibility and mobility ( 2 criteria), transport safety and security ( 3 criteria), transport economy ( 2 criteria) and transport environment ( 3 criteria). Similarly, another 8 criteria of difficulty assessment of measures are based on the transport costs
(2 criteria), technical systems (2 criteria), institutional participation ( 2 criteria) and public acceptance ( 2 criteria).

Table 5 shows the complete TM assessment modules, factors of assessment, criteria of assessment and possible indicators of assessment. The following sections describe the criteria of assessment under each traffic management factor.

Table 5 Traffic management factors, criteria and indicators

\begin{tabular}{|c|c|c|c|}
\hline $\begin{array}{l}\text { Th measures } \\
\text { assessment } \\
\text { modules }\end{array}$ & $\begin{array}{l}\text { Th factors of } \\
\text { assessment }\end{array}$ & Criteria of assessment & Possible indicators of assessment \\
\hline \multirow{12}{*}{$\begin{array}{l}\text { Effectiveness-of- } \\
\text { measures } \\
\text { assessment }\end{array}$} & \multirow{4}{*}{$\begin{array}{l}\text { Transport } \\
\text { Accessibility } \\
\text { and Uobility }\end{array}$} & $\begin{array}{l}\text { Promofion of equity of } \\
\text { transport }\end{array}$ & $\begin{array}{l}\text { Fare structure, tax subsidies, travel oppurtunities per capila, per- } \\
\text { person-km. }\end{array}$ \\
\hline & & Increase of number of routes & $\begin{array}{l}\text { \% of routes per destination, travel time, travel distance and per } \\
\text { transport mode. }\end{array}$ \\
\hline & & Increase of number of modes & Number of mode options per trip for various trip purposes. \\
\hline & & Increase of transport capacity & $\begin{array}{l}\text { Road length, number of PT stops, temninals, parking capacity, } \\
\text { service frequeny of different transpoit, etc. }\end{array}$ \\
\hline & \multirow{3}{*}{$\begin{array}{l}\text { Transport } \\
\text { Safely and } \\
\text { Securty }\end{array}$} & $\begin{array}{l}\text { Reduction of response fime of } \\
\text { trafic and ofher accidents }\end{array}$ & Response time per accident type, response time distibution, etc. \\
\hline & & $\begin{array}{l}\text { Reduction of number of trafic } \\
\text { and other accidents }\end{array}$ & $\begin{array}{l}\text { Accidents per vehicle population, accident density (accident per } \\
\text { km of road length), etc. }\end{array}$ \\
\hline & & $\begin{array}{l}\text { Reduction of severity of trafic } \\
\text { and other accidents }\end{array}$ & $\begin{array}{l}\text { Number of deaths pervehicle population, fatalities rate per year, } \\
\text { total costs of property danages per accident, etc. }\end{array}$ \\
\hline & \multirow{2}{*}{$\begin{array}{l}\text { Transport } \\
\text { Econormy }\end{array}$} & $\begin{array}{l}\text { Reduction of total transport } \\
\text { costs }\end{array}$ & $\begin{array}{l}\text { Total costs per person-kilometres, total costs per ton-kiometres, } \\
\text { total costs per activily, etc. }\end{array}$ \\
\hline & & $\begin{array}{l}\text { Maximisation of transport } \\
\text { eficiency }\end{array}$ & Time per unit passenger-km, per ton $\mathrm{km}$, per activ ly, etc. \\
\hline & \multirow{3}{*}{$\begin{array}{l}\text { Transport } \\
\text { Environment }\end{array}$} & $\begin{array}{l}\text { Minimisation of consumption } \\
\text { of energy resources }\end{array}$ & $\begin{array}{l}\text { Per capila consumption of energy, energy consumption per } \\
\text { person } k m \text {, ton km, vehicle klornetre, etc. }\end{array}$ \\
\hline & & Reduction of air pollution & $\begin{array}{l}\text { Volume of pollutant released per person kilometre, ton klornetre, } \\
\text { vehicle klometre, etc. }\end{array}$ \\
\hline & & Reduction of noise pollution & Noise levels in $\mathrm{db}(\mathrm{A})$ at different locations. \\
\hline \multirow{8}{*}{$\begin{array}{l}\text { Difficulty-of- } \\
\text { measures } \\
\text { assessment }\end{array}$} & \multirow{2}{*}{ Transport Costs } & Investment costs involved & $\begin{array}{l}\text { Total investment (infrastructure and subsidies) costs, ownership } \\
\text { costs per km., etc. }\end{array}$ \\
\hline & & $\begin{array}{l}\text { Operation and maintenance } \\
\text { costs involved }\end{array}$ & $\begin{array}{l}\text { Vehicle operating costs(Gas and ol, maintenance, tyres etc.)per } \\
\text { km., staff costs per km., etc. }\end{array}$ \\
\hline & \multirow{2}{*}{$\begin{array}{l}\text { Technical } \\
\text { Systems }\end{array}$} & $\begin{array}{l}\text { Use of operation and control } \\
\text { systems }\end{array}$ & $\begin{array}{l}\text { \% of use of manual/autornatic/intelligent traffic control and } \\
\text { operation systems, etc. }\end{array}$ \\
\hline & & Use of information systems & $\begin{array}{l}\text { Requirements of information dissernination, \% of use of dynarnic } \\
\text { and static information systems, etc. }\end{array}$ \\
\hline & \multirow[t]{2}{*}{$\begin{array}{l}\text { Institurtional } \\
\text { Participation }\end{array}$} & Imvolvement of polifical bodies & $\begin{array}{l}\text { Number of joint ventures, people, offices in olved for measure } \\
\text { inplementation, \% political and administrative opposition, Need of } \\
\text { institutional reforms, scale of inolvernent(State level), etc. }\end{array}$ \\
\hline & & $\begin{array}{l}\text { Irvolvement of transport } \\
\text { related institutions }\end{array}$ & $\begin{array}{l}\text { Number of agreernents for measure implementation, scale of } \\
\text { involvernent, etc. }\end{array}$ \\
\hline & \multirow{2}{*}{$\begin{array}{l}\text { Public } \\
\text { Acceptance }\end{array}$} & Acceptance of transport users & $\begin{array}{l}\text { \% of acceptance of transport users for TM measures, number or } \\
\% \text { of informed people,etc. }\end{array}$ \\
\hline & & $\begin{array}{l}\text { Acceptance of non-transport } \\
\text { users }\end{array}$ & $\begin{array}{l}\text { \% of acceptance of nontransport users for TM measures, number } \\
\text { or \% of informed people, etc. }\end{array}$ \\
\hline
\end{tabular}

\subsection{Effectiveness Assessment Criteria}

The level-of-effectiveness of a measure depends on the adoption of various approaches in the implementation of TM measures in disasters. Each measure is evaluated based on its effectiveness in providing equity, increasing the number of transport route options, increasing the number of transport mode options and increasing the overall capacity of the transport system. The Table 6 provides assigned scales based on description of TM measures those fulfil transport accessibility and mobility criteria as an example. The similar descriptions were made for other criteria Under transport security criteria, each measure is evaluated based on its effectiveness in reducing the response time of accidents, reducing the frequency of accidents and reducing the fatality of traffic accidents in cases of disasters. Economy of transport operations during disasters is evaluated based on its effectiveness in reducing the total transport costs and maximising the economic efficiency of existing transport systems. Where reduction of total transport costs involves the approach of reducing the total trips, maximisation of the economic efficiency involves mostly optimisation of existing transport services without trip reduction approach. Also, each measure is evaluated based on its effectiveness in reducing the consumption of energy resources, reducing the air pollution and the noise pollution related to transport. The reduction of consumption of energy in transport is mainly associated with the consumption of fossil-fuels. The reduction of air pollution is mainly related to the air emissions due to fossil-fuel transport. The reduction of noise pollution is related to operation of both fossil-fuel based and non-fossil fuel based transport modes.

While rating measures on level-of effectiveness (LOE) scales, besides the main consideration of direct criteria fulfilment of a TM measure, several other considerations are made by the participants. These considerations are that the scale varies in the increasing order of possible impact of measure i.e. low scale (LOE 1) is assigned for low impact of measures and high scale is assigned for high impact of measures (LOE 3). Directness and scale of application of measure in fulfillment of criteria is also considered, i.e. low scale is assigned when indirect promotion of use of given transport mode, minor traffic shift, minor traffic 
avoidance and minor traffic control are observed. Similarly, where use of complimentary measures is observed, low scales are assigned. Measures that involved high cost of implementation and high fuel consumption were rated low. The cost of implementation not only included minor infrastructural measures but also cost of traffic control and other operational costs.

Table 6 Description of LOE scale (Transport Safety and Security Example)

\begin{tabular}{|c|c|c|}
\hline $\begin{array}{c}\text { Transport Safety and } \\
\text { Security Criteria }\end{array}$ & $\begin{array}{l}\text { Description of Levels-of-effectiveness of } \\
\text { measure }\end{array}$ & $\begin{array}{c}\text { LOE } \\
\text { (Scale) }\end{array}$ \\
\hline \multirow{4}{*}{$\begin{array}{l}\text { To reduce the response } \\
\text { time in traffic and other } \\
\text { accidents }\end{array}$} & $\begin{array}{l}\text { This measure is dedicated to significanthy reduce the response time in } \\
\text { most traffic and other accidents by improving the road and trafic flow } \\
\text { condtions. }\end{array}$ & 3 \\
\hline & $\begin{array}{l}\text { This measure will indrectly reduce the response fime in most traffic } \\
\text { and other accidents by ether moderately improving road condtions or } \\
\text { traffic flow conditions. }\end{array}$ & 2 \\
\hline & $\begin{array}{l}\text { This measure will indrectly reduce the response fime in most traffic } \\
\text { and other acciderts by ether slightly improving road condtions or } \\
\text { traffic flow condtions. }\end{array}$ & 1 \\
\hline & This measure will have no impact on the criteria of assessment & $\mathbf{0}$ \\
\hline \multirow{4}{*}{$\begin{array}{l}\text { To reduce the number } \\
\text { of traffic accidents }\end{array}$} & $\begin{array}{l}\text { This measure will reduce accidents by imparting vehicle segregation } \\
\text { hoad safety regulations/shifting trips principles to reduce potential } \\
\text { conficts imvolving major transport modes. }\end{array}$ & 3 \\
\hline & $\begin{array}{l}\text { This measure will reduce accidents by imparting vehicle segregation } \\
\text { hoad safety regulations/shifting trips principles to reduce potential } \\
\text { conficts imvolving some transport modes. }\end{array}$ & 2 \\
\hline & $\begin{array}{l}\text { This measure will reduce accidents by imparting vehicle segregation } \\
\text { hoad safety regulations/shifting trips principles to reduce potential } \\
\text { conficts imvolving a few transport modes. }\end{array}$ & 1 \\
\hline & This measure will have no impact on the criteria of assessment & $\mathbf{0}$ \\
\hline \multirow{4}{*}{$\begin{array}{l}\text { To reduce the severity } \\
\text { of traffic accidents }\end{array}$} & $\begin{array}{l}\text { This measure will significantly reduce the fatal accidents directly by } \\
\text { minimising the potential conflicts of heavy vehicles (FT) with other } P T \text {, } \\
\text { IMT and NMT vehicles. }\end{array}$ & 3 \\
\hline & $\begin{array}{l}\text { This measure will moderately reduce the fatal accidents indrectly by } \\
\text { minimising the potential conflicts of PT and IMT vehicles with other } \\
\text { IMT and NMT vehicles. }\end{array}$ & 2 \\
\hline & $\begin{array}{l}\text { This measure will slightly reduce the fatal accidents indirectly by } \\
\text { minimising the potential conflicts of IMT and NMT vehicles with other } \\
\text { IMT and NMT vehicles. }\end{array}$ & 1 \\
\hline & This measure will have no impact on the criteria of assessment & $\mathbf{0}$ \\
\hline
\end{tabular}

Note: Level of effectiveness of measures in this category are based on improvement of traffic flow condition, traffic shift in time (in case of peak periods) and space (in cases of congested routes or locations) as well as measures that minimise the conflict between modes

\subsection{Difficulty Assessment Criteria}

Similar to the above explained level-of-effectiveness scales; level-of-difficulty scales (LOD) are developed. The LOD scales are assigned to eight difficulty criteria, which indicated the corresponding difficulties of implementation of TM measures.

The cost of the implementation of TM measures is one of many factors to estimate the applicability of a measure. Many measures that even satisfy most effectiveness and other applicability criteria may not be selected due to the high costs involved in their implementation. The transport costs difficulty criteria include: (i) the investment costs and (ii) the operation and maintenance costs. The investment costs mainly consist of cost of equipments, planning and design cost, and procurement cost of technology among other costs. The operation and maintenance costs mainly consist of staff cost, cost of traffic control, preparation and closing of traffic operation among other costs. Therefore, if these given costs are high, the selection of a measure for implementation is difficult. The low cost measures are considered favourable measures in the practice of traffic management.

In some disasters, the use of advance technical systems is often questionable due to limitations of applications e.g. unavailability of power and communications. The traffic management measures which require the technical systems for traffic operations in both urban and regional areas are often more difficult. The investigation on difficulties faced during disasters suggests the operations based on multiple forms of traffic systems and traffic technology. One of the main requirements of traffic management in disasters is the use of technical systems that are adaptive to conventional technology that aid the traffic management even during failures of power and communication. Assessment of difficulty with respect to technical systems difficulty criteria include: (i) the traffic operation and control systems, and (ii) the traffic information systems. Some of the considerations to assess the difficulty of a measure are: (i) the compatibility of traffic systems with the conventional systems (ii) the scale of modification or implementation of traffic systems, and (iii) the type of modification or implementation of traffic systems for the TM measures in disasters.

In order to select and implement the measures, institutional participation is one important pre-requisite for effective decision making, information sharing and dissemination, avoiding duplication and concentration of activities, understanding the impacts of disaster on transport system, and finally the approval of measures for the implementation. Often it is observed that involvement of various stakeholders of traffic and disaster management is almost non-existent due to overlapping roles and lack of fully functional organisation structure. This is detrimental to the effective management of disasters. Thus, in this study, the institutional participation difficulty criteria for the measure implementation include both the involvement of political bodies and transport related institutions. 
Some factors used to assess the difficulty of a measure are: (i) the level of institutional participation (national, state or city level involvement), and (ii) intensity of institutional participation (major, moderate or low involvement) for the TM measures in disasters. The investigation on difficulties of implementation of measures suggests: (i) better relationships with disaster management and traffic management stakeholders, (ii) inclusion of traffic management in pro-active and re-active phases of disaster management planning, and (iii) a coordinated training with all potential stakeholders of disaster and traffic management. Thus, the assessment of difficulty is based on difficulty of institutional participation of transport-related and political institutions.

The success of any TM measure depends largely on the public acceptance. Therefore, TM measures should intend to win the confidence of both the transport users and non-transport users by enhancing the credibility of the administration through coordinated efforts of various public agencies involved in traffic management. The transport user group consists of people using any mode of transport (pedestrians, bicyclists and drivers). Conversely, non-transport user group consists of people who do not use any mode of transport but such groups are indirectly influenced by the use of transport (transport operators, vehicle manufacturer and affected residents).

Some of the factors used to assess the difficulty of a measure related to transport users are: (i) the introduction of new transport processes (production, distribution and consumption processes), (ii) new traffic rules (traffic access restrictions on size, time and locations), (iii) changes in the travel behaviour (limited mobility), and (iv) additional costs borne by the transport users. Similarly, some factors to assess the difficulty of a measure related to nontransport users are: (i) the introduction of new transport processes (freight distribution), (ii) use of alternate vehicle technology (high costs of vehicle and a fewer buyers), (iii) degradation of quality of living (noise pollution, air pollution and land use modification), and (iv) additional costs.

While rating measures on LOD scales, besides the main considerations of criteria fulfilment of a TM measure, several other considerations are made. These considerations are that low scales are assigned for low impact of measure, indirect fulfillment of criteria, low scale of application, use of complimentary measure, indirect promotion of the use of given transport, minor effect on traffic shift/avoidance/control, high cost of implementation and high fuel consumption. Also low scales were assigned for measures that require high fuel consumption and promote low safety.

\subsection{Qualitative Assessment Model}

The qualitative assessment model is developed to calculate the final effectiveness and applicability scores of the selected twentyseven TM measures. The formula used to calculate the effectiveness and difficulty score of a TM measure is given in Formula 1 and Formula 2.In mathematical terms, the ratings obtained for measures are multiplied by relative weight of criteria and traffic management factor. This lead to reduction of rating scores as per the weights. The scores were obtained as per the weights assigned for individual measures.

The formula used to calculate the effectiveness and difficulty score considers the three different values which are: (i) the relative weight of important of $\mathrm{TM}$ factor (Wtmf), (ii) the relative weight of importance of TM criteria of assessment (WC) and (iii) the self-conducted assessment rating of the measure (LOE or LOD). In mathematical terms, the ratings obtained for measures are multiplied by relative weight of criteria and traffic management factor. This lead to reduction of rating scores as per the weights. The scores were obtained as per the weights assigned for individual measures.

$$
\mathrm{ES}(i j)=\sum_{m=1}^{4} \mathrm{Wtmf}_{m} *\left[\sum_{n=1}^{N(m)} \mathrm{WC}_{m n} * \mathrm{LOE}_{m n}^{i j}\right]
$$

Formula 1: Calculation of effectiveness score of a TM measure

where:

$$
\begin{aligned}
\mathrm{ES}_{\mathrm{ij}}= & \begin{array}{l}
\text { Effectiveness score of the TM measure ' } \mathrm{j} \text { ', } \\
\text { under TM factor ' } \mathrm{i} \text { ', }
\end{array} \\
\mathrm{Wtmf}_{\mathrm{m}}= & \begin{array}{l}
\text { Weight of traffic management factor ' } \mathrm{m} \text { ' where } \\
\mathrm{m}=1 \text { to } 4
\end{array} \\
\mathrm{WC}_{\mathrm{mn}}= & \begin{array}{l}
\text { Weight of criteria of assessment ' } \mathrm{n} \text { ', under } \\
\text { traffic management factor ' } \mathrm{m} \text { ' }
\end{array} \\
\mathrm{LOE}_{\mathrm{mn}}= & \begin{array}{l}
\text { Level of effectiveness of measure ' } \mathrm{j} \text { ' in } \\
\text { category ' } \mathrm{i} \text { ' on criteria of assessment ' } \mathrm{n} \text { ' under } \\
\text { traffic management factor ' } \mathrm{m} \text { ' }
\end{array} \\
\mathrm{N}(\mathrm{m})= & \text { Number of n; depending on } \mathrm{m}
\end{aligned}
$$

Similarly, the formula used to calculate the difficulty score of a TM measure is given in Formula 2.

$$
\mathrm{DS}(i j)=\sum_{x=1}^{4} \mathrm{Wtmf}_{x} *\left[\sum_{y=1}^{Y(x)} \mathrm{WC}_{x y} * \mathrm{LOD}_{x y}^{i j}\right]
$$

Formula 2: Calculation of difficulty score of a TM measure where:

$\begin{array}{ll}\mathrm{DS}_{\mathrm{ij}} & =\begin{array}{l}\text { Difficulty score of the TM measure ' } \mathrm{j} \text { ', under } \\ \text { TM factor ' } \mathrm{i} \text { ', }\end{array} \\ \mathrm{Wtmf}_{\mathrm{x}} & =\begin{array}{l}\text { Weight of traffic management factor ' } \mathrm{x} \text { ' } \\ \text { where } \mathrm{x}=1 \text { to } 4\end{array} \\ \mathrm{WC}_{\mathrm{xy}} & =\begin{array}{l}\text { Weight of criteria of assessment ' } \mathrm{y} \text { ', under } \\ \text { traffic management factor ' } \mathrm{x} \text { ' }\end{array} \\ \mathrm{LOD}_{\mathrm{xy}} & =\begin{array}{l}\text { Level of difficulty of measure ' } \mathrm{j} \text { ' in category } \\ \text { 'i', on criteria of assessment WC, under } \\ \text { traffic management factor ' } \mathrm{m} \text { ' }\end{array} \\ \mathrm{Y}(\mathrm{x}) & =\text { Number of y; depending on } \mathrm{x}\end{array}$

The calculation of effectiveness and difficulty scores provided the assessment of all selected measures. The priority classes are formed to check the strengths and weaknesses of measures in terms of their effectiveness in promoting accessibility and safety on one hand and optimising economy as well as ensuring environmental quality on the other. Six priority classes are composed in the order of decreasing level of effectiveness and increasing level of difficulties. Table 7 gives the detailed ranges for the formation of priority classes of TM measures. The given priority classes are instrumental in decision making about the applicability of measures in disasters. Hence, the inventory of transport infrastructural resources and their 
allocation are easier when information on type of implementable measures exist.

Table 7 Formation of priority classes of TM measures

\begin{tabular}{clcc}
\hline Priority Classes & & Effectiveness & Difficulty \\
\cline { 3 - 4 } & & Score & Score \\
\hline First Priority Group & I & ES $>2,0$ & $(0,5<\mathrm{DS}<1,5)$ \\
\hline Second Priority Group & II & ES $\leq 2,0$ & $(0,5<\mathrm{DS}<1,5)$ \\
\hline Third Priority Group & III & ES $>2,0$ & $(1,5 \leq \mathrm{DS}<2,0)$ \\
\hline Fourth Priority Group & IV & ES $\leq 2,0$ & $(1,5 \leq \mathrm{DS}<2,0)$ \\
\hline Fifth Priority Group & V & ES $>2,0$ & $(2,0 \leq \mathrm{DS}<2,5)$ \\
\hline Sixth Priority Group & VI & ES $\leq 2,0$ & $(2,0 \leq \mathrm{DS}<2,5)$ \\
\hline
\end{tabular}

Due to the proven effectiveness of twenty-seven measures in different disaster-prone and disaster-affected countries, only two ranges for effectiveness scores are set based on effectiveness score ranges which are, ES $>2.0$ and $\mathrm{ES} \leq 2.0$. Similarly, three ranges are set based on difficulties score ranges which are explained in Table 7. The complete assessment of twenty-seven TM measures obtained from effectiveness and difficulty scores of twenty-seven measures and their subsequent allocation in priority classes is given in Table 8 . The allocation of TM measures in priority classes is an attempt to reveal the applicability of TM measures for disasters. The knowledge of TM measures available from the priority classes would infer traffic managers and other disaster management stakeholders to investigate the possible solutions to improve the applicability of those measures whose difficulty scores and effectiveness scores are high. The solutions to improve the applicability may be the inclusion of other complimentary TM measures from the existing TM strategies (a group of mutually supportive measures with a plan of action) or completely new measures which might belong to non-transport sectors.

In general, the results of the qualitative assessment indicated that the TM measures which were least effective were also relatively less difficult. Conversely, the results also indicated that the most effective TM measures were relatively more difficult to implement.

\subsection{INFERENCES OF ASSESSMENT RESULTS}

Based on the six priority classes the recommended measures are obtained. The first list of recommended measures consists of first and second priority classes. The second list of recommended measures consists of third and fourth priority classes (refer Table 8). The fifth and sixth priority classes are not included in the recommended list of measures. Such measures have been referred as residual measures.

Assessment of residual measures inferred that despite high effectiveness of TM measures, some measures are difficult to implement in the local environment conditions. This study considers the residual measures for the formulation of TM strategies despite their low applicability in local conditions (disaster-affected or disaster-prone regions). The inclusion of residual measures is required primarily for the success of multiple traffic management strategies or the group of measures. Therefore, corrective actions are proposed to reduce the associated difficulties related to the implementation of such measures. A brief description of the applicability improvement methods of such measures is explained in next section.

The assessment results provided thirteen measures that were selected in the list of first recommended measures. These recommended measures included three public transport measures, two non-motorised transport measures, three individual motorised transport measures, three inter-modal and multimodal measures, and two freight transport measures (refer Table 8).

Similarly, seven measures were selected in the list of second recommended measures. These recommended measures included four public transport measures; two inter-modal and multimodal measures and one freight transport measure (refer Table 8).

A total of seven residual measures are not considered in the list of recommended measures due to their high-difficulty scores (refer Table 8).

The following gives the short inferences of the assessment results which are presented categorically based on transport modes.

\subsection{Public Transport Measures}

All public transport measures except one residual measure (PT8) qualified for the recommended measures. Such assessment results are due to high level of effectiveness of public transport measures and relatively low level of difficulty. The most recommended PT measures in disasters are: (i) Public Transport Network Improvement, (ii) Public Transport Capacity Improvement, and (iii) Public Transport Information Services. The application of these measures improves the accessibility of public transport, capacity of public transport and pubic transport use through adequate and timely information in disasters. These measures involved moderate to high costs of implementation, low to moderate use of technical systems, less involvement of stakeholders and are widely accepted by the pubic due to more benefits. The second recommended PT measures (PT-2, PT-3, PT-6 and PT-4) are effective measures but are generally costintensive measures due to high costs involved in procurement of vehicles, technology and cost of PT operations. The residual PT measure, Public Transport Management Centre is a very effective measure but it failed to qualify due to low applicability as a result of high costs of implementation, potential requirements of information collection and dissemination equipments and technology and the requirement of participation of stakeholders.

\subsection{Non-motorised Transport Measures}

Both the measures of NMT qualified for first recommended measures (NMT-1 and NMT-2). The use of pedestrian routes and bicycle routes for the short-distance trips during disasters bear a high potential to reduce the total traffic demand. The trips with shorter trip-lengths involving reduced urgency of travel can be fulfilled through this category of measures. Such measures have also a high potential to be included in inter-modal transport. Bike shelters and storage facilities can greatly promote their use, where vandalism is an issue. Also promotion of pedestrian routes will require continuity of route, uniformity of routes and a safe walking environment in disasters. The less costs involved in establishing NMT routes and facilities compared to other modes, the moderate requirement of technical systems, low requirement of stakeholders participation and high public acceptance are responsible for the inclusion of both measures in the first list of recommended measures.

\subsection{Individual Motorised Transport Measures}

Three measures of IMT qualified for first recommended measures (IMT-1, IMT-2 and IMT-3). All IMT measures addressed the immediate need of improving mobility of IMT 
users. The qualification of those recommended measures is due to low difficulties of implementation especially limited use of technical systems, limited requirement of stakeholder's participation and very low difficulties related to public acceptance. However the residual measure of IMT (IMT-4) namely 'Special Traffic Rules Enforcement' failed to qualify primarily due to poor acceptance, moderate costs of implementation and the requirement of the use of technical systems. This measure requires large scale involvement of transport and non-transport stakeholders. Additionally, this measure is highly opposed by the public due to increased inconvenience caused to public while the introduction of new rules and regulations.

Table 8 Final assessment of pre-selected TM measures

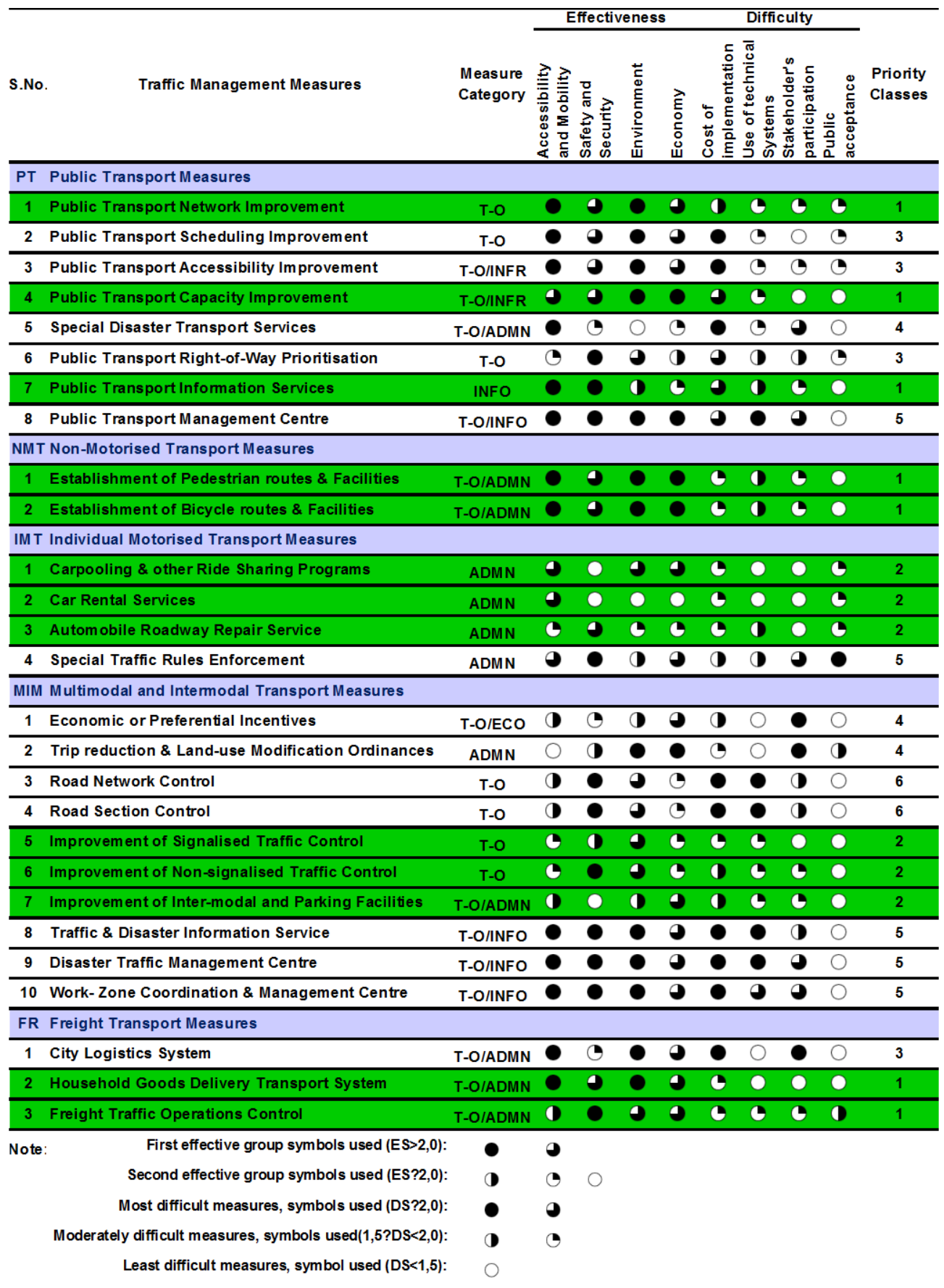

\subsection{Multi-modal and Inter-modal Transport Measures}

MIM measures are mostly cost-intensive, require high use of technical systems, require low to moderate amount and scale of stakeholder's participation and are widely accepted by the public.
Of a total of ten MIM measures, three measures qualified for first recommended measures (MIM-5, MIM-6 and MIM-7) and two measures qualified for second recommended measures (MIM-1 and MIM-2). Despite high effectiveness of the total five residual measures (MIM-3, MIM-4, MIM-8, MIM-9 and MIM-10), the 
measures indicated high costs involved in implementation, extensive requirement of use of technical systems, moderate to high involvement requirements of stakeholders and least difficulties of public acceptance.

\subsection{Freight Transport Measures}

The three selected FT measures qualified for the recommended list of TM measures (FT-1, FT-2 and FT-3). However, the assessment of measure 'City Logistics System' indicated high difficulties due to high costs and intense participation requirements of various stakeholders. The measure assessment also indicated moderate to high effectiveness of all selected measure.

In general, the traffic managers are responsible for planning, executing and assessing TM measures. Qualitative assessments are most commonly used by traffic managers due to its advantage of providing an immediate feedback. The knowledge of effective and readily applicable measures is important for traffic managers. Simultaneously the knowledge of other effective but nonapplicable measures in existing local environment is also important for traffic managers. This knowledge engages the traffic mangers in improving the applicability of TM measures in order to include measures while the formulation of TM strategies.

\subsection{SUMMARY}

This paper described the pre-selected twenty-seven traffic management measures which belong to five modes of transport and which can be applicable in the cases of disasters. The given measures are well-integrated and in line with the traffic management measures implemented in different countries. Further, the qualitative assessment of selected measures have also been conducted and discussed. The methodology of the assessment includes (i) estimation of relative weight of importance of traffic management factors using AHP technique, (ii) self-assessment and rating of measures based on effectiveness and difficulty scales, (iii) determination of priority classes of measures based on qualitative assessment model which provided the first and second recommended measures, and (iv) determination of residual measures signifying low applicability. The qualitative assessment model provided a framework to assess the effectiveness and difficulty of TM measures. Such an assessment is useful in the decision-making process for the selection of TM measures and their improvement of applicability. The results indicated that all selected measures were qualified for their effectiveness and seven measures were disqualified for their applicability.
Those measures that were disqualified as recommended measures were found to be very effective in fulfilling the goals and criteria of traffic management in cases of disasters e.g. Traffic \& Disaster Information Service, Disaster Traffic Management Centre and Work-Zone Coordination \& Management Centre. The results indicated that costs of implementation and requirement of advanced technical systems were found as main hindrances in the application of measures followed by the stakeholder participation. The public acceptance is the least difficult factor in the application of TM measures.

Although the residual measures were found inapplicable due to high difficulties of implementation in the local environment yet these measures form a good basis of inclusion due to very high levels of effectiveness. This fact cannot be simply ignored and such measures should be used in the formulation of traffic management strategies only after prior reduction of their implementation difficulties. Thus, the applicability improvement methods for residual measures should be further researched through empirical studies of disaster-prone or affected areas.

\section{Acknowledgement}

The Author (Principal Investigator) does hereby acknowledge Ministry of Higher Education (MOHE) and Universiti Teknologi Malaysia (UTM) for providing funding for research project (Vote Number 07J06) and Research Management Center (RMC) for logistical assistance throughout the duration of this project.

\section{References}

[1] Bluman, A. Elementary Statistics: A Step by Step Approach. Fifth Version. New York: McGraw-Hill Company Inc. ISBN: 0-07-254907-

[2] Gercek, H., Karpak, B. and Kilincaslan, T. 2004. A Multiple Criteria Approach for the Evaluation of the Rail Transit Networks in Istanbul. Journal-Transportation. Springer Netherlands, Netherlands. ISSN: 0049-4488, Netherlands. 203-228.

[3] Minhans, A. 2008. Traffic Management Strategies in Cases of Disasters. Fachgebiet Verkehrsplanung und Verkehrstechnik. ISSN: 1613-8317, Darmstadt, Germany.

[4] Parida, P. Najamuddin, Parida, M. 2007. Development of qualitative evaluation methodology for sidewalks in Delhi. ITPI Journal. ISSN 0537-9649, New Delhi. 4(3): 27-33

[5] Saaty, T. 1959. Mathematical Methods of Operations Research. McGraw-Hill Company Inc. Maple Press Company, York.

[6] Saaty, T. 2000. Fundamentals of Decision Making and Priority Theory with Analytic Hierarchy Process. RWS Publications. ISBN 0962031763, Pittsburg. 6. 